\title{
PROPRIEDADES DO SOLO, ESTADO NUTRICIONAL E PRODUTIVIDADE DE BANANEIRAS 'PRATA ANÃ' (AAB) IRRIGADAS COM ÁGUAS CALCÁRIAS ${ }^{1}$
}

\author{
Soil properties, nutritional status and yield of 'prata anã' (aab) banana plants \\ under irrigation with calcareous water
}

\author{
José Tadeu Alves da Silva², Janice Guedes de Carvalho ${ }^{3}$
}

\begin{abstract}
RESUMO
Com o objetivo de verificar os efeitos da irrigação utilizando águas calcárias sobre algumas propriedades químicas e físicas do solo, sobre os teores de nutrientes nas folhas e na produtividade de bananeiras 'Prata Anã', foram selecionados 100 bananais no norte de Minas Gerais, sendo 50 bananais irrigados com águas calcárias e 50 irrigados com águas não-calcárias. Verificou-se que os bananais irrigados com águas calcárias apresentaram maior teor foliar de Ca, maior produtividade e solos com maiores valores de $\mathrm{pH}$, condutividade elétrica, teores de $\mathrm{Ca}$ e matéria orgânica e menor densidade em relação àqueles irrigados com águas não-calcárias.
\end{abstract}

Termos para indexação: Banana, nutrição, água calcária, solo.

\section{SUMMARY}

The effects of the irrigation using calcareous water on some chemical and physical properties of the soil, on the foliar nutrient content and on the productivity of 'Prata Anã' (AAB) banana crops were evaluated. A total of 100 commercial banana crops were selected, being 50 commercial banana crops irrigated with calcareous water. It was verified that the banana crops irrigated with calcareous water presented greater foliar content of $\mathrm{Ca}$, greater produtivity and the soils of these banana crops presented greater $\mathrm{pH}$, eletric conductivity, $\mathrm{Ca}$ and organic matter content and smaller density in relation to those irrigated with non calcareous water.

Index terms: Banana, nutrition, calcareous water, soil.

(Recebido para publicação em 30 de junho de 2003 e aprovado em 19 de setembro de 2003)

\section{INTRODUÇÃO}

No norte de Minas Gerais há aproximadamente 15.000 ha de áreas irrigadas cultivadas com bananeiras. De acordo com Souza et al. (1999), os solos predominantes nessas áreas são classificados como Neossolo Quartzarênico órtico, Latossolo Vermelho Amarelo distrófico, Latossolo Vermelho eutrófico e Neossolo Flúvico Tb eutrófico. Em torno de 50\% dessas áreas são irrigadas com águas calcárias provenientes de poços tubulares, que se caracterizam por apresentar elevadas concentrações de $\mathrm{Ca}^{+2}, \mathrm{CO}_{3}^{-2}$ e $\mathrm{HCO}_{3}^{-}$. Segundo Maia et al. (2001), a utilização de águas com elevadas concentrações de $\mathrm{CO}_{3}^{-2}$ e $\mathrm{HCO}_{3}^{-}$, em áreas irrigadas continuamente, eleva o $\mathrm{pH}$ do solo. $\mathrm{O}$ aumento do $\mathrm{pH}$ e dos teores de $\mathrm{Ca}$ do solo para níveis elevados podem promover desequilíbrio de nutrientes na bananeira, que é muito sensível ao desequilíbrio entre $\mathrm{Ca}, \mathrm{K}$ e $\mathrm{Mg}$. Se- gundo Silva et al. (1999), sintomas de deficiência de K podem ser observados quando os teores de $\mathrm{Ca}$ e $\mathrm{Mg}$ no solo são elevados. Em áreas irrigadas com águas calcárias, pode ocorrer desequilíbrio entre esses nutrientes, em razão do aumento dos teores de Ca do solo.

Uma forma de identificar águas calcárias é pelo cálculo do ISL (Índice de Saturação de Langelier). Esse índice é definido pela diferença entre o $\mathrm{pH}$ atual da água e o $\mathrm{pH}_{\mathrm{c}}$, que é o $\mathrm{pH}$ teórico que a água alcançaria em equilíbrio com o $\mathrm{CaCO}_{3}$ (AYERS e WESTCOT, 1991).

Quando o ISL é positivo, indica uma água super-saturada com $\mathrm{CaCO}_{3}$; quando é negativo, indica uma água subsaturada com $\mathrm{CaCO}_{3} \mathrm{e}$, quando ISL for igual a zero, significa que a água está em equilíbrio com o $\mathrm{CaCO}_{3}$. Geralmente, águas calcárias apresentam valores de ISL positivos.

Costa e Gheyi (1984) avaliaram a qualidade das águas da região de Catolé do Rocha $(\mathrm{PB})$ e verificaram

\footnotetext{
1. Trabalho financiado pela FAPEMIG

2. Engenheiro Agrônomo/EPAMIG, Estudante do Curso de Doutorado do Departamento de Ciência do Solo da Universidade Federal de Lavras/UFLA, Caixa Postal 37 - 37200-000 - Lavras, MG, tadeu@ufla.br

3. Engenheira Agrônoma, Dra. em Nutrição de Plantas, Professora Titular do Departamento de Ciência do Solo da UFLA.
} 
que grande parte das águas apresentavam elevadas concentrações de $\mathrm{HCO}_{3}^{-}$, $\mathrm{Ca}, \mathrm{Mg}$ e Na. Resultados semelhantes foram encontrados por Maia et al. (1997) na avaliação da qualidade das águas de poços tubulares, de rios e de açudes da Chapada do Apodi (RN). A salinização pode causar no solo, entre outros processos, mudanças nas suas propriedades químicas e físicas (BERNARDO, 1995).

A irrigação com águas calcárias favorece o acúmulo de sais nos solos, o que possibilita a ocorrência de várias reações. Costa (2000), trabalhando com um Latossolo Vermelho amarelo álico, em Mossoró (RN), observou que o pH original do solo de 5,2 passou para 7,8 com aplicação diária de água com concentração de $\mathrm{CO}_{3}^{-2}$ e $\mathrm{HCO}_{3}^{-}$de 0,6 e $2,1 \mathrm{mmol}_{\mathrm{c}} \mathrm{L}^{-1}$, respectivamente. Em trabalho realizado com o objetivo de avaliar o efeito da irrigação com água calcária sobre as propriedades químicas do solo, no norte de Minas Gerais, Silva et al. (2001) verificaram que o pH do solo elevou-se em torno de 1,4 unidade, em apenas quatro anos de irrigação com água calcária. De acordo com esses autores, o pH é a propriedade do solo que mais afeta a disponibilidade dos micronutrientes e de fósforo.

A estabilidade dos agregados do solo é proporcional à floculação das partículas de argila. Se a argila permanece dispersa, o solo torna-se pouco permeável, com poucos poros e, portanto, com baixa aeração. Por essa razão, as plantas apresentam baixo desenvolvimento nesses solos. Para reduzir a dispersão de argila em solos com elevados valores de PST (Porcentagem de sódio total), recomenda-se a aplicação de calcário $\left(\mathrm{CaCO}_{3}\right.$ e $\left.\mathrm{MgCO}_{3}\right)$ e/ou gesso $\left(\mathrm{CaSO}_{4}\right)$, pelo fato de o $\mathrm{Ca}$ e $\mathrm{Mg}$ possuírem maiores forças de floculação das argilas do que o $\mathrm{Na}$ e, portanto, aumentam a estabilidade dos agregados do solo (KEREN e MIYAMOTO, 1990; QADIR et al., 1996). Segundo esses autores, a adição de cátions divalentes reduz a dispersão de argila do solo. $\mathrm{Na}$ aplicação de gesso, em solos com argilas dispersas em consequiência da presença de elevadas concentrações de $\mathrm{Na}$, o $\mathrm{Ca}$ do gesso substitui o $\mathrm{Na}$, nos sítios de trocas do solo, o que reduz a espessura da DCD (Dupla camada difusa), resultando na floculação da argila, aumento na estabilidade da estrutura e da permeabilidade do solo.

A irrigação com água rica em $\mathrm{Ca}$ e $\mathrm{Mg}$ favorece a floculação da argila. Nos solos irrigados com águas calcárias, geralmente predominam os cátions divalentes e a relação entre $\mathrm{Na} / \mathrm{Ca}+\mathrm{Mg}$ é baixa, de onde se pode inferir que esses solos tendem a apresentar partículas de argila floculadas e, conseqüentemente, boa permeabilidade. Por outro lado, o aumento do $\mathrm{pH}$ de solos ácidos reduz a concentração de $\mathrm{Al}^{+3}$ na solução do solo, permitindo que cátions com menor valência em relação ao $\mathrm{Al}^{+3}$ passem a dominar o complexo de troca do solo, favorecendo a expansão da DCD. Para um Latossolo Vermelho-Escuro, Jucksch (1987) constatou que a aplicação de $\mathrm{CaCO}_{3}$ e $\mathrm{MgCO}_{3}$ elevou o $\mathrm{pH}$, as cargas negativas e ocorreu precipitação do $\mathrm{Al}$ do solo. $\mathrm{O}$ autor verificou que a substituição do $\mathrm{Al}$ pelo $\mathrm{Ca}$ e o aumento das cargas negativas provocaram a expansão da DCD, aumentando a quantidade de argila dispersa e causando desestabilização dos agregados do solo. Segundo o autor, o $\mathrm{Al}^{+3}$ possui maior força de floculação que o $\mathrm{Ca}^{+2}$.

Realizou-se este trabalho com o objetivo de avaliar os efeitos da irrigação com águas calcárias sobre algumas propriedades químicas e físicas dos solos, o estado nutricional e a produtividade de bananeiras 'Prata Anã' (AAB), cultivadas no norte de Minas Gerais.

\section{MATERIAL E MÉTODOS}

Foram selecionados 100 bananais explorados comercialmente com bananeiras 'Prata Anã' (AAB) com idades entre 2 a 4 anos, localizados no semiárido do norte de Minas Gerais. Desses bananais, 50 eram irrigados com águas calcárias de poços tubulares e, 50, irrigados com águas não-calcárias provenientes de rios (Tabela 1).

Em cada bananal foram marcadas 20 plantas no início do florescimento. Dessas plantas, coletouse a $3^{\mathrm{a}}$ folha, a partir do ápice, retirando-se $10 \mathrm{~cm}$ central de cada folha, eliminando-se a nervura central. Nas amostras de folhas, foram analisados os macro e micronutrientes, conforme descritos em Malavolta et al. (1989). Os cachos de banana colhidos em cada planta marcada foram despencados e pesados.

Amostras de solo foram coletadas na profundidade de 0 a $20 \mathrm{~cm}$, em cada bananal, em pontos próximos às plantas marcadas. Cada amostra de solo foi composta de 20 amostras simples. Para análise da densidade dos solos, foram utilizadas amostras coletadas em anéis volumétricos, na profundidade de $5 \mathrm{~cm}$. As análises químicas e de densidade foram realizadas segundo métodos descritos em EMBRAPA (1979). 
TABELA 1 - Valores médios do pH, condutividade elétrica (CE), concentrações de cálcio (Ca), magnésio $(\mathrm{Mg})$, sódio $(\mathrm{Na})$, carbonato $\left(\mathrm{CO}_{3}^{-2}\right)$, bicarbonato $\left(\mathrm{HCO}_{3}^{-}\right)$e dos índices de saturação de Langilier (ISL) de águas calcárias provenientes de poços tubulares e de águas não-calcárias provenientes de rios, coletadas no semiárido do norte de Minas Gerais, 2002.

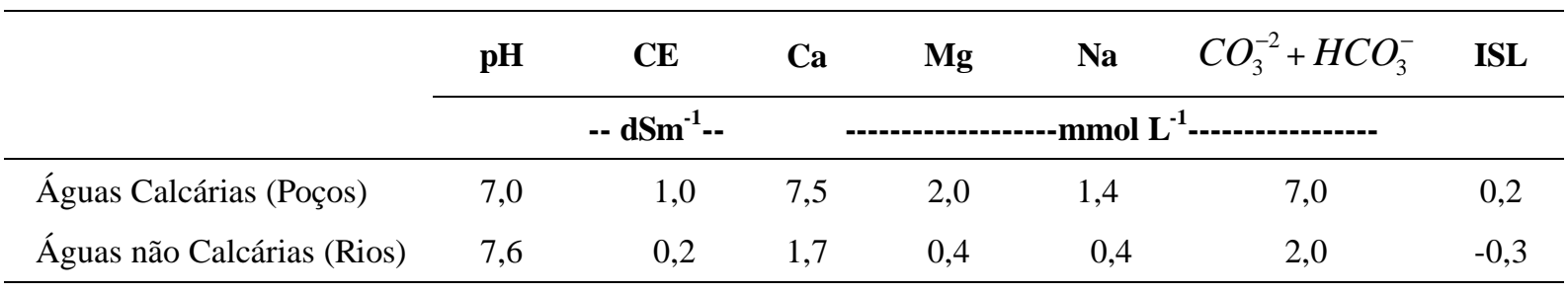

Os solos predominantes, tanto nas áreas irrigadas com águas calcárias como nas áreas irrigadas com águas não-calcárias, foram classificados como Neossolo Quartzarênico órtico, Latossolo Vermelho Amarelo distrófico, Latossolo Vermelho eutrófico e Neossolo Flúvico Tb eutrófico (SOUZA et al., 1999).

De acordo com o questionário realizado, todos os bananais onde foram coletados os dados foram adubados com cloreto de potássio, uréia, sulfato de amônio, sulfato de magnésio, sulfato de zinco e ácido bórico. As adubações variaram de acordo com as análises de solo e folhas, conforme recomendações para o norte de Minas Gerais propostas por Silva (1995).

$\mathrm{O}$ delineamento experimental utilizado foi o inteiramente casualizado, com dois tratamentos e 50 repetições. Os resultados obtidos das análises de solo, de folhas e da produção foram analisados estatísticamente pela análise de variância e teste de médias. Foram determinados os coeficientes de correlação entre o pH, os teores dos nutrientes no solo com a produtividade e os teores de nutrientes nas folhas das bananeiras.

\section{RESULTADOS E DISCUSSÃO}

As águas dos poços tubulares apresentaram ISL positivos e foram classificadas como calcárias, enquanto as águas provenientes de rios apresentaram ISL negativos, sendo classificadas como águas não-calcárias (Tabela 1), conforme descrito em Botelho (1999).

De acordo com os dados apresentados na Tabela 2 , verificou-se que a produtividade das bananeiras, o $\mathrm{pH}$, os teores de Ca e matéria orgânica, a CE e a densidade do solo diferiram estatisticamente entre os solos irrigados com águas calcárias e não-calcárias. Verificou-se que os solos irrigados com águas calcárias, no norte de Minas Gerais, apresentaram teor médio de $\mathrm{Ca}$ duas vezes maior e valor médio de $\mathrm{pH}$ superior em uma unidade em relação àqueles irrigados com águas não calcárias (Tabela 3). Isso ocorreu porque as concentrações de $\mathrm{Ca}$ e $\mathrm{HCO}_{3}^{-}$são 4,4 e 3,5 vezes, respectivamente, maiores nas águas calcárias em relação às águas não-calcárias (Tabela 1).

Para o bom desenvolvimento da bananeira, a relação $\mathrm{K}: \mathrm{Ca}: \mathrm{Mg}$ no solo deve ser de 0,5: 3,5: 1,0 a 0,3: 2,0: 1,0 (MARTIN-PRÉVEL, 1985). Verificou-se que os solos irrigados com águas não-calcárias apresentaram relação $\mathrm{K}: \mathrm{Ca}: \mathrm{Mg}$ com melhor equilíbrio em relação aos solos irrigados com águas calcárias (Tabela 3). Ainda assim, as bananeiras irrigadas com águas calcárias apresentaram produtividade média significativamente maior em relação àquelas irrigadas com águas não-calcárias (Tabela 3).

A relação $\mathrm{K} / \mathrm{Na}$ adequada no solo é em torno de 2,5 e o Na não deve exceder $8 \%$ do total de cátions trocáveis, sendo o ideal inferior a 4\% (DELVAUX, 1995). Para os solos irrigados com águas calcárias e nãocalcárias, os valores médios da relação $\mathrm{K} / \mathrm{Na}$ obtidos foram de 2,5 e 2,0, respectivamente. $\mathrm{O}$ teor de $\mathrm{Na}$ encontrado nos solos irrigados com águas calcárias e nãocalcárias representou 2 e 3,5\% do total de cátions trocáveis, respectivamente. Portanto, a quantidade de $\mathrm{Na}$ presente nos solos não apresentou nenhum risco de toxidez para as bananeiras cultivadas no semi-árido do norte de Minas Gerais.

A densidade do solo é uma propriedade física que reflete o arranjamento das partículas do solo (FERREIRA et al., 2003). Esse arranjamento está relacionado com a dispersão e floculação da argila. Geralmente, solos com alto grau de argilas floculadas e alto teor de matéria orgânica tendem a apresentar menores valores de densidades. Segundo Ferreira et al. (2003), os valores de densidade podem ser diminuídos pela incorporação de matéria orgânica ao solo. $\mathrm{O}$ valor médio 
das densidades dos solos irrigados com águas calcárias apresentou-se significativamente menor em relação àquele dos solos irrigados com águas não-calcárias (Tabela 3). Esse comportamento está coerente com os dados da literatura, que mostram maior grau de floculação das partículas de argila, estruturas mais estáveis e baixos valores de densidades em solos que apresentam maiores valores de $\mathrm{CE}$, elevados teores de $\mathrm{Ca}$ (GRUPTA et al., 1984; NADLER et al., 1996; RAHIMI et al., 2000) e matéria orgânica (FERREIRA et al., 2003). O teor médio de Ca nos solos irrigados com águas calcárias apresentou-se duas vezes maior, e a CE, em torno de $50 \%$ maior que aquela dos solos irrigados com águas não-calcárias (Tabela 3), o que favoreceu a menor densidade nos solos irrigados com águas calcárias. O teor médio de matéria orgânica dos solos irrigados com águas calcárias foi significativamente maior (Tabela 3), favorecendo, também, para o menor valor de densidade obtido para esses solos. Solos que apresentam baixa densidade favorecem o melhor desenvolvimento radicular das plantas que, por sua vez, favorecem o aumento de produtividade.
Os teores de nutrientes das folhas não diferiram entre as bananeiras irrigadas com águas calcárias e não-calcárias, com exceção do $\mathrm{Ca}$ (Tabela 4), que apresentou teor médio significativamente maior nas folhas das bananeiras irrigadas com águas calcárias (Tabela 5), refletindo o maior teor desse elemento no solo.

De acordo com López \& Espinosa (1995), os nutrientes foliares apresentam-se equilibrados quando as relações $\mathrm{K} / \mathrm{K}+\mathrm{Ca}+\mathrm{Mg}, \mathrm{Ca} / \mathrm{K}+\mathrm{Ca}+\mathrm{Mg}$ e $\mathrm{Mg} / \mathrm{K}+\mathrm{Ca}+\mathrm{Mg}$, expressos em miliequivalentes $(\% \mathrm{~K} / 0,039, \% \mathrm{Ca} / 0,020$ e $\% \mathrm{Mg} / 0,012$ ) apresentam valores de 55 a $61 \%, 20$ a $27 \%$ e 18 a $20 \%$, respectivamente. Baseado nos teores médios de nutrientes foliar apresentados na Tabela 5, verificou-se que as folhas das bananeiras irrigadas com águas calcárias apresentaram valores de 56, 23 e 22\% para as relações $\mathrm{K} / \mathrm{K}+\mathrm{Ca}+\mathrm{Mg}, \mathrm{Ca} / \mathrm{K}+\mathrm{Ca}+\mathrm{Mg}$ e $\mathrm{Mg} / \mathrm{K}+\mathrm{Ca}+\mathrm{Mg}$, respectivamente, e as bananeiras irrigadas com águas não-calcárias apresentaram valores de 62,16 e $21 \%$, respectivamente. Portanto, as bananeiras irrigadas com águas calcárias apresentaram melhor equilíbrio entre os teores foliar de $\mathrm{K}, \mathrm{Ca}$ e $\mathrm{Mg}$.

TABELA 2 - Valores de F da análise de variância das variáveis produtividade das bananeiras (Prod.), pH, teores de K, P, Ca, Mg, Na e matéria orgânica (M.O), condutividade elétrica (CE) e densidade de amostras de solo (Ds), coletadas no semi-árido do norte de Minas Gerais, 2002.

\begin{tabular}{|c|c|c|c|c|c|c|c|c|c|c|c|}
\hline Fonte de variação & G.L & Prod & pH & $\mathbf{K}$ & $\mathbf{P}$ & $\mathbf{C a}$ & Mg & $\mathbf{N a}$ & M.O & $\mathbf{C E}$ & Ds \\
\hline Tratamentos: & & & & & & & & & & & \\
\hline $\begin{array}{l}\text { (Água calcária e } \\
\text { água não calcária) }\end{array}$ & 1 & $5,5 *$ & $68,2 * *$ & $2,6^{\mathrm{ns}}$ & $1,6^{\mathrm{ns}}$ & $61,1 * *$ & $0,1^{\mathrm{ns}}$ & $0,2^{\mathrm{ns}}$ & $33,6 * *$ & $7,6 * *$ & $27,4 * *$ \\
\hline Resíduo & 98 & & & & & & & & & & \\
\hline C.V (\%) & & 22,0 & 11,4 & 60,5 & 85,9 & 37,8 & 57,9 & 58,3 & 37,8 & 62,1 & 11,8 \\
\hline
\end{tabular}

Não-significativo (ns) e significativo a $5 \%(*)$ e $1 \%(* *)$ de probabilidade.

TABELA 3 - Valores médios do pH, condutividade elétrica (CE), teores de $\mathrm{P}, \mathrm{K}, \mathrm{Ca}, \mathrm{Mg}, \mathrm{Na}$ e matéria orgânica (M.O), densidade do solo (Ds) e da produtividade (prod.) de bananeiras irrigadas com águas calcárias e nãocalcárias no semi-árido do norte de Minas Gerais, 2002.

\begin{tabular}{|c|c|c|c|c|c|c|c|c|c|c|}
\hline $\begin{array}{c}\text { Classificação da } \\
\text { água }\end{array}$ & 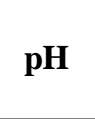 & $\begin{array}{c}\mathrm{CE} \\
\mathrm{dS} \mathbf{m}^{-1}\end{array}$ & $\begin{array}{c}P \\
\mathrm{mg} \mathrm{dm}^{-3}\end{array}$ & $\mathbf{K}$ & $\begin{array}{r}\mathrm{Ca} \\
--\mathrm{cmo}\end{array}$ & Mg & $\mathrm{Na}$ & $\begin{array}{l}\text { M.O } \\
\mathrm{g} \mathrm{kg}^{-1}\end{array}$ & $\begin{array}{c}\text { Ds } \\
\mathrm{kg} \mathrm{dm}^{-3}\end{array}$ & 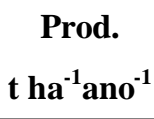 \\
\hline Águas Calcárias & & $0,62 \mathrm{a}$ & $33,0 \mathrm{a}$ & $0,5 \mathrm{a}$ & & & $0,2 \mathrm{a}$ & $27 \mathrm{a}$ & $1,5 \mathrm{a}$ & $34,2 \mathrm{a}$ \\
\hline Águas não calcárias & $5,0 \mathrm{~b}$ &, $44 \mathrm{~b}$ & 26,5 a & $0,4 \mathrm{a}$ & $4,1 \mathrm{~b}$ & $1,0 \mathrm{a}$ & $0,2 \mathrm{a}$ & $17 \mathrm{~b}$ & $1,7 \mathrm{~b}$ & $30,9 \mathrm{~b}$ \\
\hline
\end{tabular}

Médias seguidas da mesma letra, na coluna, não diferem entre si pelo teste de Tukey a $5 \%$ de probalidade. 
Os teores de nutrientes encontrados nas folhas das bananeiras irrigadas com águas calcárias (Tabela 5) estavam dentro das faixas de suficiência estabelecidas por Silva et al. (2002), para bananeira 'Prata Anã' alcançar alta produtividade. Diante desses resultados, verificou-se que a irrigação com águas calcárias no norte de Minas não causou nenhuma limitação nutricional às bananeiras.

Ocorreram correlações significativas entre a produtividade da bananeira e os teores de $\mathrm{P}, \mathrm{Ca}$ e $\mathrm{Mg}$ do solo (Tabela 6). O maior teor de Ca nos solos irrigados com águas calcárias contribuiu para que as bananeiras cultivadas nessas áreas apresentassem maior produtividade. Segundo Furtini Neto et al. (2001), o Ca é o nu- triente mais importante para o crescimento de raízes, favorecendo o aumento da absorção de água e nutrientes pelas plantas.

$\mathrm{O} \mathrm{pH}$ do solo correlacionou-se positivamente com o teor foliar de $\mathrm{Ca}$ e negativamente com os teores foliar de P, S e Mn. À medida que o pH do solo se eleva, a disponibilidade de Mn reduz (SOUZA, 1999; FURTINI NETO et al., 2001). Em solos com elevados valores de $\mathrm{pH}$ e alto teor de $\mathrm{Ca}$, ocorre precipitação de $\mathrm{P}$, reduzindo a sua disponibilidade para as bananeiras (SILVA et al., 2001). O aumento do teor de $\mathrm{Ca}$ no solo elevou o teor de $\mathrm{Ca}$ foliar e reduziu o teor de $\mathrm{S}$ nas folhas das bananeiras (Tabela 6).

TABELA 4 - Valores de F da análise de variância dos teores de nutrientes das folhas de bananeiras cultivadas no semi-árido do norte de Minas Gerais, 2002.

\begin{tabular}{lccccccccccccc}
\hline Fonte de Variação & $\mathbf{G . L}$ & $\mathbf{N}$ & $\mathbf{P}$ & $\mathbf{K}$ & $\mathbf{C a}$ & $\mathbf{M g}$ & $\mathbf{S}$ & $\mathbf{B}$ & $\mathbf{C u}$ & $\mathbf{F e}$ & $\mathbf{N a}$ & $\mathbf{M n}$ & $\mathbf{Z n}$ \\
\hline Tratamentos: & & & & & & & & & & & & & \\
$\begin{array}{l}\text { (Água Calcária e } \\
\text { água não calcária) }\end{array}$ & 1 & $1,0^{\mathrm{ns}}$ & $1,0^{\mathrm{ns}}$ & $0,1^{\mathrm{ns}}$ & $8,5^{* *}$ & $0,2^{\mathrm{ns}}$ & $1,2^{\mathrm{ns}}$ & $1,4^{\mathrm{ns}}$ & $0,1^{\mathrm{ns}}$ & $0,2^{\mathrm{ns}}$ & $0,1^{\mathrm{ns}}$ & $0,1^{\mathrm{ns}}$ & $0,7^{\mathrm{ns}}$ \\
Resíduo & & & & & & & & & & & & & \\
\hline C.V $(\%)$ & 98 & & & & & & & & & & & & \\
\hline
\end{tabular}

Não-significativo (ns), significativo a $5 \%(*)$ e $1 \%(* *)$ de probabilidade.

TABELA 5 - Teores médios de nutrientes nas folhas de bananeiras 'Prata Anã' irrigadas com águas calcárias e águas não-calcárias no semi-árido do norte de Minas Gerais, 2002.

\begin{tabular}{|c|c|c|c|c|c|c|c|c|c|c|c|c|}
\hline Classificação da água & $\mathbf{N}$ & $\mathbf{P}$ & $\mathbf{K}$ & $\mathbf{C a}$ & Mg & $\mathbf{S}$ & B & $\mathbf{C u}$ & $\mathbf{F e}$ & Mn & $\mathrm{Na}$ & $\mathbf{Z n}$ \\
\hline & \multicolumn{12}{|c|}{ 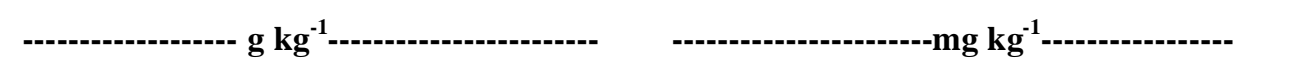 } \\
\hline Águas calcárias & $27 \mathrm{a}$ & $1,7 \mathrm{a}$ & $31 \mathrm{a}$ & $6,3 a$ & $3,7 \mathrm{a}$ & $2,0 \mathrm{a}$ & $30 \mathrm{a}$ & $5,9 \mathrm{a}$ & $115 \mathrm{a}$ & $410 \mathrm{a}$ & $36,4 a$ & $17 \mathrm{a}$ \\
\hline Águas não Calcárias & $26 \mathrm{a}$ & $1,7 \mathrm{a}$ & $32 \mathrm{a}$ & $4,1 b$ & $3,4 \mathrm{a}$ & $2,1 \mathrm{a}$ & $29 a$ & $5,7 \mathrm{a}$ & $114 a$ & $335 \mathrm{a}$ & $36,9 \mathrm{a}$ & $16 \mathrm{a}$ \\
\hline C.V \% & 11,1 & 12,3 & 14,7 & 24,0 & 25,0 & 20,5 & 23,8 & 27,1 & 36,3 & 81,6 & 54,3 & 27,1 \\
\hline
\end{tabular}

Médias seguidas da mesma letra, na coluna, não diferem entre si, pelo teste de Tukey a $5 \%$ de probabilidade. 
Tabela 6 - Coeficientes de correlação entre teores de nutrientes e pH dos solos com teores de nutrientes foliar e produtividade (Prod.) de bananeiras 'Prata Anã' irrigadas com águas calcárias e águas não-calcárias no semi-árido do norte de Minas Gerais, 2002.

\begin{tabular}{|c|c|c|c|c|c|c|}
\hline \multirow{2}{*}{$\begin{array}{l}\text { Nutrientes } \\
\text { foliar }\end{array}$} & \multicolumn{6}{|c|}{ Propriedades química do solo } \\
\hline & pH & $\mathbf{P}$ & $\mathbf{K}$ & $\mathbf{C a}$ & Mg & $\mathrm{Na}$ \\
\hline Prod. & $0,106^{\mathrm{ns}}$ & $0,332 * *$ & $0,140^{\text {ns }}$ & $0,378 * *$ & $0,308^{*}$ & $0,196^{\mathrm{ns}}$ \\
\hline $\mathrm{N}$ & $-0,233^{\text {ns }}$ & $-0,047^{\mathrm{ns}}$ & $-0,062^{\text {ns }}$ & $-0,041^{\text {ns }}$ & $-0,065^{\mathrm{ns}}$ & $0,086^{\mathrm{ns}}$ \\
\hline $\mathrm{P}$ & $-0,289^{*}$ & $0,011^{\mathrm{ns}}$ & $0,064^{\mathrm{ns}}$ & $-0,149^{\text {ns }}$ & $-0,096^{\mathrm{ns}}$ & $-0,094^{\text {ns }}$ \\
\hline K & $-0,022^{\text {ns }}$ & $-0,073^{\text {ns }}$ & $0,138^{\text {ns }}$ & $-0,075^{\text {ns }}$ & $0,090^{\mathrm{ns}}$ & $-0,042^{\text {ns }}$ \\
\hline $\mathrm{Ca}$ & $0,361 * *$ & $0,110^{\text {ns }}$ & $-0,113^{\text {ns }}$ & $0,476^{* *}$ & $-0,052^{\text {ns }}$ & $0,211^{\mathrm{ns}}$ \\
\hline $\mathrm{Mg}$ & $0,117^{\mathrm{ns}}$ & $-0,035^{\mathrm{ns}}$ & $-0,131^{\mathrm{ns}}$ & $0,230^{\mathrm{ns}}$ & $0,234^{\mathrm{ns}}$ & $0,485^{* *}$ \\
\hline S & $-0,301 *$ & $-0,156^{\mathrm{ns}}$ & $-0,088^{\text {ns }}$ & $-0,255^{*}$ & $-0,204^{\mathrm{ns}}$ & $0,002^{\mathrm{ns}}$ \\
\hline B & $-0,124^{\mathrm{ns}}$ & $-0,060^{\text {ns }}$ & $-0,060^{\text {ns }}$ & $0,030^{\text {ns }}$ & $0,286^{*}$ & $0,174^{\mathrm{ns}}$ \\
\hline $\mathrm{Cu}$ & $0,202^{\mathrm{ns}}$ & $0,151^{\mathrm{ns}}$ & $0,150^{\mathrm{ns}}$ & $-0,061^{\text {ns }}$ & $-0,205^{\text {ns }}$ & $-0,015^{\mathrm{ns}}$ \\
\hline $\mathrm{Fe}$ & $0,231^{\mathrm{ns}}$ & $-0,014^{\mathrm{ns}}$ & $0,167^{\mathrm{ns}}$ & $0,226^{\text {ns }}$ & $0,123^{\mathrm{ns}}$ & $-0,031^{\mathrm{ns}}$ \\
\hline $\mathrm{Mn}$ & $-0,379 * *$ & $-0,136^{\mathrm{ns}}$ & $-0,127^{\text {ns }}$ & $-0,190$ & $-0,230^{\mathrm{ns}}$ & $-0,050^{\text {ns }}$ \\
\hline $\mathrm{Na}$ & $0,140^{\mathrm{ns}}$ & $0,268^{*}$ & $0,186^{\mathrm{ns}}$ & $-0,044^{\text {ns }}$ & $-0,146^{\mathrm{ns}}$ & $-0,014^{\mathrm{ns}}$ \\
\hline $\mathrm{Zn}$ & $0,175^{\mathrm{ns}}$ & $0,110^{\mathrm{ns}}$ & $0,125^{\text {ns }}$ & $0,080^{\mathrm{ns}}$ & $0,098^{\mathrm{ns}}$ & $0,179^{\mathrm{ns}}$ \\
\hline
\end{tabular}

Não-significativo (ns), significativo a $5 \%(*)$ e $1 \%(* *)$ de probabilidade.

\section{CONCLUSÕES}

As bananeiras irrigadas com águas calcárias apresentaram maior produtividade e maior teor de $\mathrm{Ca}$ nas folhas em relação àquelas irrigadas com águas nãocalcárias.

A utilização de águas calcárias na irrigação não influenciou a absorção de nutrientes pelas bananeiras, com exceção do $\mathrm{Ca}$.

Os solos dos bananais irrigados com águas calcárias apresentaram maiores $\mathrm{pH}, \mathrm{CE}$, teores de $\mathrm{Ca}$ e matéria orgânica e menores valores de densidade.

\section{REFERÊNCIAS BIBLIOGRÁFICAS}

AYERS, R. S.; WESTCOT, D. W. A qualidade da água na agricultura. Tradução de: GHEYI, H. R.; MEDEIROS, J. F.; DAMASCENO, F. A .V. Campina Grande: UFPB, 1991. 218 p. (Estudos FAO: Irrigação e Drenagem, 29).

BERNARDO, S. Manual de Irrigação. 6. ed. Viçosa: UFV, 1995. $657 \mathrm{p}$.
BOTELHO, C. G. Qualidade da água para irrigação. Lavras: UFLA/FAEPE, 1999. 96 p.

COSTA, R. G.; GHEYI, H. R. Variação da água de irrigação da microregião homogênea de Catolé do Rocha, PB. Pesquisa Agropecuária Brasileira, Brasília, v. 19, p. 1021-1025, 1984.

COSTA, S. A. D. Resposta do arroz à adubação fosfatada associada à correção do solo com calcário e metassilicato de cálcio em Latossolo vermelhoamarelo álico sob condições de casa de vegetação. Mossoró: ESAM, 2000. 20 p.

DELVAUX, B. Soil. In: GOWEN, S. Bananas and plantains. New York: Chapman \& Hall, 1995. p. 230-257.

EMPRESA BRASILEIRA DE PESQUISA AGROPECUÁRIA. Manual de métodos de análise de solo. Rio de Janeiro: EMBRAPA/CNPS, 1979. Não paginado.

FERREIRA, M. M.; DIAS JÚNIOR, M. S.; MESQUITA, M. G. B. F.; ALVES, E. A. B. F. Física do solo. Lavras: UFLA/FAEPE, 2003. 79 p. 
FURTINI NETO, A. E.; VALE, F. R. do; RESENDE, A. V. de; GUILHERME, L. R. G.; GUEDES, G. A. A. Fertilidade do solo. Lavras: UFLA/FAEPE, 2001. 252 p.

GRUPTA, R. K.; BHUMBLA, D. K.; ABROL, I. P. Effect of sodicity $\mathrm{pH}$, organic matter and

calcium carbonate on the dispersion behavior of soils. Soil Science, Madison, v. 137, p. 245-251, 1984.

JUCKSCH, I. Calagem e dispersão de argila em amostra de um Latossolo Vermelho-Escuro. 1987. 37 f. Dissertação (Mestrado) - Universidade Federal de Viçosa, Viçosa, 1987.

KEREN, R.; MIYAMOTO, S. Reclamation of saline, sodic and boron-affected soils. In: TANI, K. K. (Ed.). Agricultural salinity assesment and management: ASCE manuals and reports or engineering praticem. New York: Society of Civil Engineering, 1990. p. 410431.

MAIA, C. E.; MORAIS, E. R. C.; OLIVEIRA, M. Qualidade da água para fertirrigação por gotejamento. I: região da Chapada do Apodí-RN. Engenharia na Agricultura, [S.1.], v. 5, p. 281-292, 1997.

MAIA, C. E.; MORAIS, E. R.C. de; OLIVEIRA, M de. Estimativa de carbonato de cálcio aplicado via água de irrigação nas regiões da Chapada do Apodi e Baixo Açu, RN. Revista Brasileira de Engenharia Agrícola e Ambiental, Campina Grande, v. 5, n. 2, p. 271-275, 2001.

MALAVOLTA, E.; VITTI, G. C.; OLIVEIRA, S. A. Avaliação do estado nutricional das plantas: princípios e aplicações. Piracicaba: POTAFOS, 1989. 201 p.

MARTIN-PRÉVEL, P. Exigências nutricionais da bananicultura. In: SIMPÓSIO BRASILEIRO SOBRE BANANICULTURA, 1., 1984, Jaboticabal. Anais... Jaboticabal. UNESP/FCAV, 1985. p. 118-134.
NADLER, P. N.; LEVY, G. J.; KEREN, R.; EISENBERG, $\mathrm{H}$. Sodic calcareous soil reclamation as affected by water chemical composition and flow rate. Soil Science Society of America Journal, Madison, v. 60, p. 252-257, 1996.

QADIR, M.; QURESHI, R. H.; AHMAD, N. Reclamation of a saline-sodic soil by gypsum and Leptochloa fusca. Geoderma, [S.1.], v. 74, p. 207-217, 1996.

RAHIMI, H.; PAZIRA, E.; TAJIK, F. Effect of soil organic matter, eletrical conductivity and sodium adsorption ratio on tensile strength of aggregates. Soil and Tillage Research, Amsterdam, v. 54, p. 145-153, 2000.

SILVA, E. B.; RODRIGUES, M. G. V.; SANTOS, J. O. Estado nutricional de um bananal irrigado com água subterrânea. In: SIMPÓSIO NORTE MINEIRO SOBRE A CULTURA DA BANANA, 1., 2001, Nova Porteirinha. Anais... Nova Porteirinha: EPAMIG, 2001. p. 203-217.

SILVA, J. T. A. da. Adubação e nutrição da bananeira para o norte de Minas. Belo Horizonte: EPAMIG, 1995. 24 p. (Boletim Técnico, 46).

SILVA, J. T. A.; BORGES, A. L.; DIAS, M. S. C.; COSTA, E. L.; PRUDÊNCIO, J. M. Diagnóstico nutricional da bananeira prata anã para o norte de Minas. Belo Horizonte: EPAMIG, 2002. 16 p. (Boletim Técnico, 70).

SILVA, J. T. A.; BORGES, A. L.; MALBURG, J. L. Solos, adubação e nutrição da bananeira. Informe Agropecuária, Belo Horizonte, v. 6, n. 63, p. 18-21, 1999.

SOUZA, L. S.; BORGES, A. L.; SILVA, J. T. A. da. Características físicas e químicas de solos cultivados com bananeira, sob irrigação, na região Norte de Minas Gerais. Cruz das Almas: EMBRAPA Mandioca e Fruticultura, 1999. 24 p. (Boletim de Pesquisa, 14). 